\title{
Effect of vermicompost and its mixtures with water treatment residuals on soil chemical properties and barley growth
}

\author{
E.K. Mahmoud* and M.M. Ibrahim \\ Department of soil and water science, Faculty of Agriculture, Tanta University, Egypt. ${ }^{*}$ Corresponding author: \\ dr_3esawe@yahoo.com
}

\begin{abstract}
Water treatment residuals (WTR) and organic amendments can improve both organic wastes recycling and soil reclamation. The present work was carried out to evaluate the effect of vermicompost, when used alone or in combination with WTR at mixed ratios of 2:1 and 1:1 wet weight (Vermi: WTR ), on soil chemical properties of saline sodic soils, and on barley growth (Hordeum aestivm). The results showed that the soil EC, SAR, $\mathrm{Cl}^{-}$and $\mathrm{Na}^{+}$decreased significantly with the application of vermicompost alone and when mixed with WTR. Organic matter, CEC and nutrients available $(\mathrm{N}, \mathrm{P}$ and $\mathrm{K})$ were increased as the rate of the organic materials increased. The treatment of vermicompost: WTR (2:1 wet weight ratio) at level of $10 \mathrm{~g} \mathrm{~kg}^{-1}$ soil gave the highest grain weight of barley plants compared to other treatments. Based on the results of the current study, the combinations of vermicompost and WTR can are considered as an ameliorating material to reclaim of salt- affected soils and to improve the yield of barley plants. Moreover, it can improve the efficiency of organic wastes and WTR disposal.
\end{abstract}

Keywords: Vermicompost, Amendments, Reclamation, Barley, Disposal. 


\section{Introduction}

The total salt affected soil areas in the world are about 955 Mega ha (FAO, 1995), of which 0.9 Mega ha occur are in Egypt. Under saline conditions, dissolved salts may accumulate in soils and inhibit plant growth. The three main problems caused by sodium-induced dispersion are reduced infiltration, reduced hydraulic conductivity, and surface crusting (Qadir and Schubert, 2002). The improvement of soil physical and chemical properties in salt-affected soils may be achieved by using good quality water, soil amendments, good drainage and appropriate cultural practices (Grattan and Oster, 2003). In this respect, the development of the most suitable reclamation technology or a combination of technologies may be critical to optimize farm management for better crop yields in salt-affected soils. Although several reclamation techniques have been researched, including physical, biological and chemical treatment, limited literature is available on the combination of vermicompost and water treatment residuals to improve salt-affected soils.

Many researchers such as (Wahdan et al., 1999) used different soil conditioners (e.g. organic manures, mineral fertilizers, sulfur and gypsum) to reclaim some chemical and physical properties of different soils. Vermicomposts, which are stabilized organic materials produced by earthworms and microorganisms, have been reported to improve plant germination growth and yields in greenhouse crops (Edwards et al., 2004). Vermicompost have large particulate surface areas that provide many micro sites for microbial activity, strong retention of nutrients, high nutrients content and rich microbial populations (Atiyeh et al., 2000c).

Natural organic matter and suspended solids are removed from surface water for water treatments using coagulation/sedimentation by aluminium (Al) as coagulate agents (Bursill, 2001). Water treatment residuals (WTR) are produced as a by-product of these treatments. The disposal of these by-products is a direct discharge to water bodies as disposal methods. Because of the high cost of landfill disposal, the application of WTR to agricultural land can be considered as a possible alternative. However, this has caused concerns due to their content in $\mathrm{Al}$ and potential contaminants, and their ability to bind phosphorus (Lombi et al., 2010). Park et al., (2010) reported that the WTR was likely to be used as a growth medium. It was used with rice straw compost reduce the bioavailability of heavy metals and to increase the yield of canola grown in contaminated soil (Mahmoud, 2011).

The application of WTR with compost as soil amendment improved chemicals (such as soil salinity and sodicity) and increased the yield of wheat grown on salt affected soils (Mahmoud et al., 2009).

Barley plant is considered one of the most important cereal crops in Egypt. It is actually very important and can be considered as a moderate salt tolerant plant crop in arid regions, as well as in poor and saline soils (Abd El-Hady, 2007)

The objective of this study is to investigate the effect of vermicompost with and without water treatment residuals (WTR) at mixed ratios of 2:1 and 1:1 wet $\mathrm{w}$ eight (Vermi: WTR ), on the chemical properties of saline sodic soils and on the growth of barley (Hordeum aestivm).

\section{Materials and methods}

Composite soil samples from twenty samples were collected from the agricultural soils of Baltiem area, Kafer El-Sheikh water Governorate, Egypt. The samples taken from the upper $30 \mathrm{~cm}$ soil layer were air - dried, ground and sieved through 2-mm sieve to increase the uniformity of the experiment. The par- 
ticle size distribution of the used soil is $36.21 \%$ silt, $29.61 \%$ sand and $34.18 \%$ clay with texture grade of clay loam. Its main characteristics were $0.92 \%$ organic matter, $25.82 \mathrm{dS} \mathrm{m}^{-1} \mathrm{EC}, 42.24 \%$ ESP and 8.56 $\mathrm{pH}$. Accordingly, this soil may be classified as a saline sodic soil (Brady, 1999).

\subsection{Experiment and treatments}

Barley (Hordeum aestivm) plants were grown in pots in a completely randomized experimental design with five replicates. Pots ( 35 pots) with $25 . \mathrm{cm}$ diameter and $35 \mathrm{~cm}$ depth were used in this study. Each pot was filled with $15 \mathrm{~kg}$ of the used fine soil and planted with (30) of barley seeds. Vermicompost (Vermi), used alone or in combination with water treatment residuals (WTR) at mixed ratios of 1:1 and 2:1 wet weight (Vermi: WTR), were added at rates of 5 and $10 \mathrm{~g}$ on dry weight basis per kg air-dried soil and then mixed thoroughly. The treatments used were: T0: Control; T1: $5 \mathrm{~g}$ of Vermicompost $\mathrm{kg}^{-1}$ soil; $\mathrm{T} 2$ : $10 \mathrm{~g}$ of Vermicompost $\mathrm{kg}^{-1}$ soil;
T3: $5 \mathrm{~g}$ of Vermi + WTR (1:1) $\mathrm{kg}^{-1}$ soil; T4: $10 \mathrm{~g}$ of Ver$\mathrm{mi}+$ WTR (1:1) $\mathrm{kg}^{-1}$ soil; T5: $5 \mathrm{~g}$ of Vermi + WTR (2:1) $\mathrm{kg}^{-1}$ soil and T6:10g of Vermi + WTR (2:1) $\mathrm{kg}^{-1}$ soil

The recommended inorganic fertilizers were added in the forms of ammonium sulfate for $\mathrm{N}$, superphosphate for $\mathrm{P}$ and potassium sulfate for $\mathrm{K}$ at the rates $30 \mathrm{~kg} \mathrm{~N}, 25 \mathrm{~kg} \mathrm{P}_{2} \mathrm{O}_{5}$ and $50 \mathrm{~kg} \mathrm{~K}_{2} \mathrm{O}$ per fed (fed= $4200 \mathrm{~m}^{2}$ ), respectively. Barley plant was harvested after 12 weeks from planting. Plant organs were washed with tap water then rinsed with distilled water and dried in an oven at $60-70^{\circ} \mathrm{C}$ for $72 \mathrm{hr}$. The oven grain weight was recorded. After the harvesting of barely plants, the soil samples were taken from each replicate and prepared for chemical analysis.

The vermicompost used in this experiment was made of rice straw and animal wastes with local species of earthworm such as Eisenia andrei (Oligochaeta) and Eisenia fetida. Water treatment residuals (WTR) were collected from Kafer El-Dewar water treatment plant. The properties of the used soils, WTR and veremicompost are given in Table (1).

Table 1. Physical and chemical properties of the studied soil samples and soil amendments.

\begin{tabular}{lcccc}
\hline Properties & Units & $\begin{array}{c}\text { Soil } \\
(\mathbf{n = 2 0})\end{array}$ & $\begin{array}{c}\text { Vermicompost } \\
(\mathbf{n = 3})\end{array}$ & $\begin{array}{c}\text { WTR } \\
(\mathbf{n}=\mathbf{3})\end{array}$ \\
\hline $\mathrm{pH}$ & & 8.56 & 7.6 & 7.62 \\
$\mathrm{EC}$ & $\mathrm{dS} \mathrm{m}$ & 4.65 & 3.23 \\
$\mathrm{Ca}^{++}$ & 25.82 & 16.3 & 20.3 \\
$\mathrm{Mg}^{++}$ & meq l-1 & 85.3 & 12.6 & 5.3 \\
$\mathrm{Na}^{+}$ & meq l-1 & 70.2 & 20.3 & 6.3 \\
$\mathrm{~K}^{+}$ & meq 1-1 & 166.5 & 3.2 & 2.9 \\
$\mathrm{Al}^{3+}$ & meq l-1 & 1.4 & & 3315 \\
$\mathrm{Cl}^{-}$ & mg kg-1 & & 31.5 & 28.8 \\
$\mathrm{HCO}_{3}^{-}$ & meq l-1 & 102.0 & 3.6 & 2.5 \\
$\mathrm{SAR}^{-1}$ & meq l-1 & 2.56 & 5.34 & 1.76 \\
$\mathrm{CaCO}_{3}$ & & 18.8 & & \\
\hline
\end{tabular}


Continued...

\begin{tabular}{lcccc}
\hline Properties & Units & $\begin{array}{c}\text { Soil } \\
(\mathbf{n = 2 0})\end{array}$ & $\begin{array}{c}\text { Vermicompost } \\
(\mathbf{n}=\mathbf{3})\end{array}$ & $\begin{array}{c}\text { WTR } \\
(\mathbf{n}=\mathbf{3})\end{array}$ \\
\hline $\mathrm{OM}$ & $\%$ & 0.92 & 32.6 & 4.86 \\
$\mathrm{Clay}$ & $\%$ & 34.18 & & 65.7 \\
Total heavy metals & & & \\
$\mathrm{Cd}$ & $\mathrm{mg} \mathrm{kg}^{-1}$ & & 4.3 & 6.4 \\
$\mathrm{Zn}$ & $\mathrm{mg} \mathrm{kg}^{-1}$ & & 40.6 & 39.7 \\
$\mathrm{Ni}$ & $\mathrm{mg} \mathrm{kg}^{-1}$ & & 10.4 & 19.6 \\
$\mathrm{~Pb}$ & $\mathrm{mg} \mathrm{kg}^{-1}$ & & 19.6 & 43.5 \\
\hline
\end{tabular}

Organic carbon of soils and WTR were determined according to Walkely- Black rapid titration method, as outlined by Page (1982). Based on the assumption that organic matter contains $58 \%$ organic carbon the organic matter was calculated by multiplying the organic carbon value by the Van Bemmelen of 1.724. Whereas, the organic matter of vermicompost was calculated as the difference between ash and dry weight $(50 \%$ of $\mathrm{OM}$ was considered organic $\mathrm{C})$ (AFNOR 1991). The $\mathrm{pH}$ and $\mathrm{EC}$ were determined in extract of the saturated vermicompost, WTR and soils by means of using $\mathrm{pH}$ and electrical conductivity meters, respectively. The content of soluble cations $\left(\mathrm{Na}^{+} \mathrm{Mg}^{++}, \mathrm{Ca}^{++}, \mathrm{K}^{+}\right)$and anions $\left(\mathrm{HCO}_{3}^{-}\right.$and $\left.\mathrm{Cl}^{-}\right)$ was determined in soil paste extract as described by Black (1982). Cationic exchange capacity (CEC) of the soils and WTR was determined by means of using sodium-ammonium acetate saturation technique (Page, 1982). The total nitrogen in raw materials was determined by Kjeldahl method (Page, 1982). Available phosphorus was extracted using $\mathrm{NaHCO}_{3} 0.5$ $\mathrm{N}$ and determined by using of spectrophotometer at wave length of $650 \mathrm{~nm}$, as described by Black (1982). Available potassium was extracted using ammonia solution $1 \%$ and determined using flame photometer as described by Page (1982). Total heavy metals concentration was measured by atomic absorption after wet digesting the air dried WTR and vermicompost using the mixture of concentrated $\mathrm{H}_{2} \mathrm{SO}_{4}$ and $\mathrm{H}_{2} \mathrm{O}_{2}$, Black (1982). Clay of WTR and soils was measured by the international standard pipette methods using sodium hexameta-phosphate as dispersing agent according to Black (1982). Grain weight of barley plants was determined by drying in the oven at $60-70^{\circ} \mathrm{C}$ for 72 hours and then weighed. Treatment mean differences were statistically analyzed by the least significant difference $\left(\mathrm{LSD}_{0.05}\right)$ test (SAS, 1996)

\section{Results}

\subsection{Effect of vermicompost and its mixtures with WTR on the soil chemical properties}

\section{Salinity and sodicity}

Figure 1 shows the reduction percentage of the soil salinity (EC) and sodicity (SAR) affected by the individual applications of vermicompost and in combination at different mixed ratios of WTR. With different treatments under study, the resulted reductions as a percentages (\%) of EC and SAR were ranged from 16.8 and $36.0 \%$ to 39.0 and $46.0 \%$ with the addition of vermicompost at level of $5 \mathrm{~g} \mathrm{~kg}^{-1}$ soil and mixed ratio of $2: 1$ (Vermi:WTR) at rate of $10 \mathrm{~g} \mathrm{~kg}^{-1}$ soil, 
respectively. The application of vermicompost when used alone and in combination with WTR at the two mixed ratios had a significant effect on the reduction percentage of EC and SAR compared to the unamend- ed soil. The mixture of treatments vermicompost and WTR (2:1 wet weight ratio) at level of $10 \mathrm{~g} \mathrm{~kg}^{-1}$ soil showed the greatest reduction in both EC and SAR compared with other treatments.

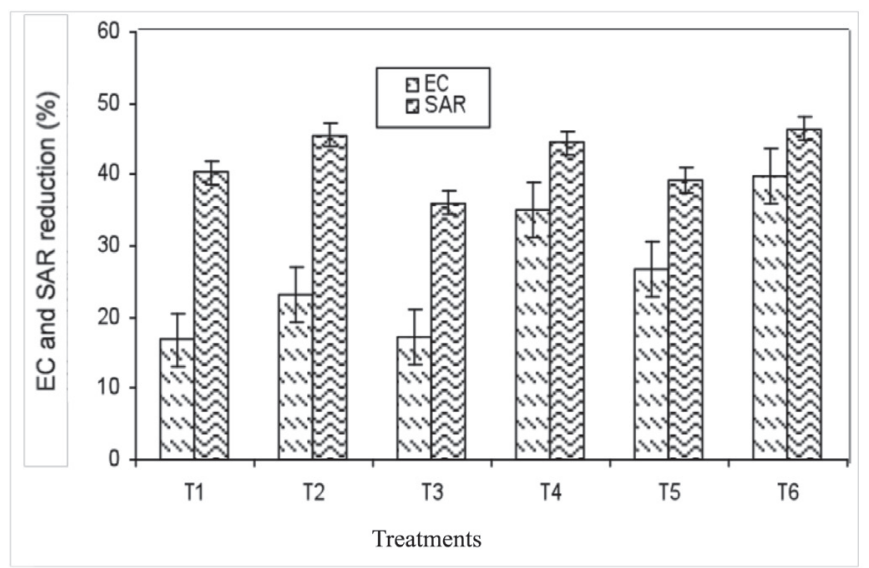

Figure 1. The reduction percentage of EC and SAR as affected by the application of vermicompost, and WTR/ vermicompost mixture. Values are means \pm standard error $(\mathrm{n}=3)$. T0: Control; T1: Vermicompost at $5 \mathrm{~g} \mathrm{~kg}^{-1} \mathrm{soil}$; T2: Vermicompost at $10 \mathrm{~g} \mathrm{~kg}^{-1}$ soil; T3: Vermi + WTR (1:1) at $5 \mathrm{~g} \mathrm{~kg}^{-1}$ soil; T4: Vermi + WTR (1:1) at $10 \mathrm{~g} \mathrm{~kg}^{-1}$ soil; T5: Vermi + WTR (2:1) at $5 \mathrm{~g} \mathrm{~kg}^{-1}$ soil; T6: Vermi + WTR (2:1) at $10 \mathrm{~g} \mathrm{~kg}^{-1}$ soil.

\section{Available nitrogen, phosphorus and potassium}

Application of vermicompost alone at rate of 5 and $10 \mathrm{~g} \mathrm{~kg}^{-1}$ soil increased significantly the $\mathrm{NaHCO}_{3}$ extractable $\mathrm{P}\left(\mathrm{mg} \mathrm{kg}^{-1}\right)$ values by $43 \%$ and $70 \%$ over the control (Table 3), respectively. The $\mathrm{NaHCO}_{3}$ extractable P did not differ significantly $(p \leq 0.05)$ as affected by the interaction treatments of vermicompost and WTR. Soil treated with vermicompost at rate of $10 \mathrm{~g}$ $\mathrm{kg}^{-1}$ soil had more $\mathrm{NaHCO}_{3}$ extractable $\mathrm{P}$ than those resulted from other treatments.

The soil content $\left(\mathrm{mg} \mathrm{kg}^{-1}\right)$ of available nitrogen $(\mathrm{N})$ and potassium $(\mathrm{K})$ increased with individual additions of vermicompost or in combination with WTR compared to the control (Table 3). The highest content of available $\mathrm{N}$ and $\mathrm{K}$ was found in the pots treated with $10 \mathrm{~g}$ vermicompost $\mathrm{kg}^{-1}$ soil, whereas the lowest was recorded in the control. The available nitrogen and potassium increased with the increase of the application rates of vermicompost when used alone and in combination with WTR (Table 3). These increases were more pronounced in the pots treated with vermicompost alone than these associated the treatments of WTR and vermicompost mixtures.

Organic matter, CEC, $p H$ and soluble cations and anions

The soil content (\%) of organic matter and CEC was increased clearly and significantly at the level of $p<0.05$ followed by the soil treated by different ratios of vermicompost alone and its in combination with WTR (Table 3). Soil pH was decreased as a result of vermicompost application especially at high applica- 
tion rate, whereas the interaction treatments of vermicompost and WTR effect on soil pH generally were changed slightly (Table 2).

Different applications of vermicompost when used alone or in combination with WTR reduced significantly the soil content (meq/l) of $\mathrm{Cl}^{-}$and $\mathrm{Na}^{+}$. The found decreases were more clear in the combination applications (Table 2). The addition of $10 \mathrm{~g}$ vermicom- post $\mathrm{kg}^{-1}$ soil at 2:1 ratio of vermicompost: WTR gave the highest reduction in the content of soluble $\mathrm{Cl}^{-}$and $\mathrm{Na}^{+}$followed by the treatment of $10 \mathrm{~g}$ vermicompost $\mathrm{kg}^{-1}$ soil at 1:1 ratio of vermicompost: WTR. The content of soluble carbonate was similar in all treatments while the content of soluble bicarbonate was slightly increased with all treatments.

Table 2. Effect of vermicompost, WTR and vermicompost/WTR mixtures on salinity, soluble cations and anions in the studied soil after barley harvesting.

\begin{tabular}{|c|c|c|c|c|c|c|c|c|}
\hline \multirow[b]{2}{*}{ Treatments } & \multirow[b]{2}{*}{$\mathbf{p H}$} & \multirow{2}{*}{$\begin{array}{l}\text { ECd } \\
\text { Sm }^{-1}\end{array}$} & \multicolumn{2}{|c|}{ Cations } & \multicolumn{2}{|c|}{ meql $^{-1}$} & \multicolumn{2}{|c|}{ Anions } \\
\hline & & & $\mathrm{Ca}^{++}$ & $\mathbf{M g}^{++}$ & $\mathbf{N a}^{+}$ & $\mathbf{K}^{+}$ & $\mathrm{Cl}^{-}$ & $\mathrm{HCO}_{3}^{-}$ \\
\hline Control & 8.63 & 10.66 & 14.23 & 16.07 & 81.95 & 0.93 & 53.88 & 2.42 \\
\hline Vermicompost at $5 \mathrm{~g} \mathrm{~kg}^{-1}$ soil & 7.42 & 8.87 & 17.12 & 18.23 & 53.22 & 1.25 & 45.82 & 2.58 \\
\hline Vermicompost at $10 \mathrm{~g} \mathrm{~kg}^{-1}$ soil & 7.23 & 8.20 & 18.62 & 20.26 & 50.62 & 1.91 & 42.23 & 2.58 \\
\hline Vermi + WTR (1:1) at $5 \mathrm{~g} \mathrm{~kg}^{-1}$ soil & 7.83 & 8.82 & 16.73 & 18.21 & 56.43 & 0.99 & 46.62 & 2.38 \\
\hline Vermi + WTR (1:1) at $10 \mathrm{~g} \mathrm{~kg}^{-1}$ soil & 7.74 & 6.92 & 12.62 & 15.32 & 43.7 & 1.08 & 35.32 & 2.83 \\
\hline Vermi + WTR (2:1) at $5 \mathrm{~g} \mathrm{~kg}^{-1}$ soil & 7.66 & 7.82 & 14.60 & 16.20 & 50.3 & 1.12 & 38.89 & 2.58 \\
\hline Vermi + WTR (2:1) at $10 \mathrm{~g} \mathrm{~kg}^{-1}$ soil & 7.63 & 6.42 & 12.35 & 13.20 & 40.35 & 1.06 & 32.62 & 2.42 \\
\hline L.S.D at level 0.05 & 1.01 & 1.65 & 1.8 & 2.7 & 24.8 & 0.66 & 6.8 & 0.33 \\
\hline
\end{tabular}

Table 3. Effect of vermicompost and vermicompost/WTR mixtures on CEC, OM and available P, N and K in the studied soil after barley harvesting.

\begin{tabular}{|c|c|c|c|c|c|}
\hline \multirow[b]{2}{*}{ Treatments } & \multirow{2}{*}{$\begin{array}{c}\text { CEC } \\
\text { C mol } 100 \mathrm{~g}^{-1} \\
\text { soil }\end{array}$} & \multirow{2}{*}{$\underset{\%}{\text { O.M }}$} & \multicolumn{3}{|c|}{ Available, $\mathrm{mg} \mathrm{kg}^{-1}$ soil } \\
\hline & & & $\mathbf{P}$ & $\mathbf{K}$ & $\mathbf{N}$ \\
\hline Control & 32.92 & 0.86 & 30.93 & 35.37 & 635 \\
\hline Vermicompost at $5 \mathrm{~g} \mathrm{~kg}^{-1}$ soil & 36.19 & 1.52 & 44.32 & 77.37 & 683 \\
\hline Vermicompost at $10 \mathrm{~g} \mathrm{~kg}^{-1}$ soil & 37.34 & 1.55 & 52.72 & 92.95 & 687 \\
\hline Vermi + WTR (1:1) at $5 \mathrm{~g} \mathrm{~kg}^{-1}$ soil & 33.57 & 1.25 & 39.72 & 74.07 & 637 \\
\hline Vermi + WTR (1:1) at $10 \mathrm{~g} \mathrm{~kg}^{-1}$ soil & 34.66 & 1.43 & 39.89 & 87.27 & 636 \\
\hline Vermi + WTR (2:1) at $5 \mathrm{~g} \mathrm{~kg}^{-1}$ soil & 34.92 & 1.45 & 37.68 & 77.59 & 644 \\
\hline Vermi + WTR (2:1) at $10 \mathrm{~g} \mathrm{~kg}^{-1}$ soil & 35.79 & 1.51 & 39.84 & 83.80 & 636 \\
\hline L.S.D at level 0.05 & 0.59 & 0.32 & 5.78 & 24.0 & 11.0 \\
\hline
\end{tabular}


3.2 Effect of vermicompost and its mixtures with WTR on grain weight of barley plants

Grain weight (g/plant) of barley plants increased significantly in soil treated by vermicompost alone or in combination with WTR at mixed ratios of 2:1 and 1:1 at both level of 5 and $10 \mathrm{~g}$ dry weight $\mathrm{kg}^{-1}$ dry soil and vermicompost at rate of $10 \mathrm{~g} \mathrm{~kg}^{-1}$ soil compared with other treatments (Figure 2). High grain weight of barley plants was obtained with the treatment of $10 \mathrm{~g}$ vermicompost $\mathrm{kg}^{-1}$ soil mixed with WTR at ratio of 2:1 compared to other treatments. The relative increase (RI \%) of grain weight of barley plants ranged from $18.0 \%$ with the treatment of 1:1 (Vermi: WTR) ratio to $89.3 \%$ with the addition of $10 \mathrm{~g}$ vermicompost $\mathrm{kg}^{-1}$ soil at mixed ratio of 2:1 vermicompost: WTR. The relative increase of grain weight of barley plants differed significantly between the studied treatments.

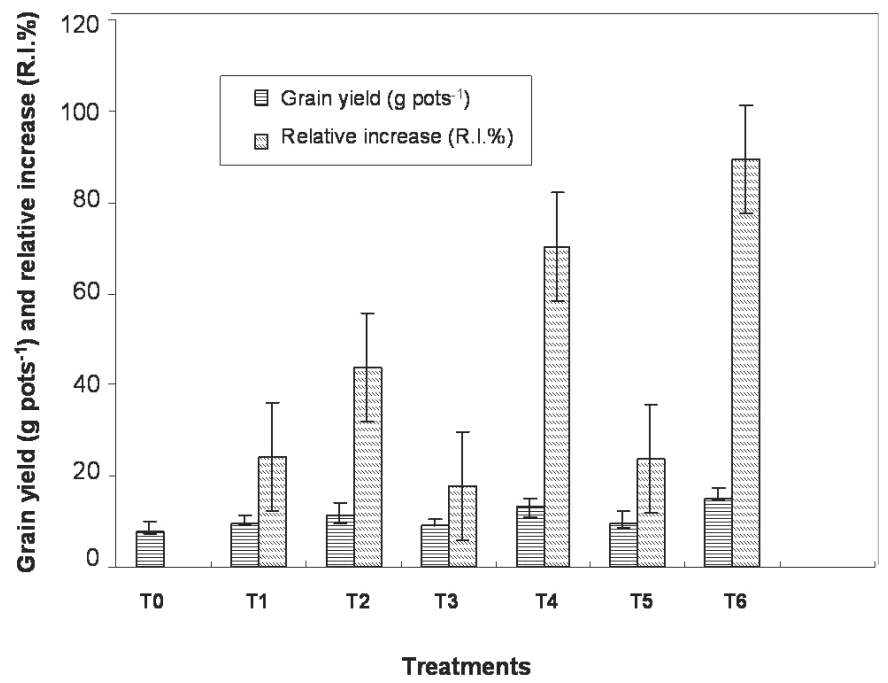

Figure 2. Grain yield and relative increase (R.I) of barley plants as affected by the applied soil amendment levels. Values are means \pm standard error $(\mathrm{n}=3)$. T0: Control; T1: Vermicompost at $5 \mathrm{~g} \mathrm{~kg}^{-1}$ soil; $\mathrm{T} 2$ : Vermicompost at 10 $\mathrm{g} \mathrm{kg}^{-1}$ soil; T3: Vermi + WTR (1:1) at $5 \mathrm{~g} \mathrm{~kg}^{-1}$ soil;T4: Vermi + WTR (1:1) at $10 \mathrm{~g} \mathrm{~kg}^{-1}$ soil; T5: Vermi + WTR (2:1) at $5 \mathrm{~g} \mathrm{~kg}^{-1}$ soil; T6: Vermi + WTR (2:1) at $10 \mathrm{~g} \mathrm{~kg}^{-1}$ soil.

\section{Discussion}

\subsection{Effect of vermicompost and its mixtures with WTR on the soil chemical properties}

The SAR takes into account the adverse effect of sodium when moderated by the presence of calcium and magnesium ions. It is generally considered that a SAR value above 12 or 15 indicates that serious soil problems will occur (i.e. permeability and tilth). This means that plants may have difficulty in absorbing water (Brady, 1999). The reduction of soil salinity and sodicity with vermicompost and its mixture with WTR may be due to vermicompost and WTR which allows continuous supply of $\mathrm{Ca}^{++}, \mathrm{Mg}{ }^{++}$and other cations, in addition to $\mathrm{Al}^{3+}$ which exists in the WTR. These cations lead to replace the exchangeable $\mathrm{Na}^{+}$ from soil matrix and to form new stable aggregates. 
These processes increase hydraulic conductivity and encourage the water to flow down and leach the salt out (Aggag and Mahmoud, 2006). The application of organic matter to salt-affected soil promotes flocculation of clay minerals, which is an essential condition for the aggregation of soil particles. It also plays an important role in increasing biopores spaces, which increase $\mathrm{Na}^{+}$leaching. Consequently, decreased the exchangeable sodium percentage (ESP) and the electrical conductivity (Lakhdar et al., 2008).

Phosphorus is one of the most essential plant nutrients. Salinity and sodicity can affect forms and dynamics of phosphorus in soil (Dominguez et al., 2001). The increase of $\mathrm{NaHCO}_{3}$ - extractable $\mathrm{P}$ with vermicompost may be attributed to the release of humic acid during organic matter decomposition, results in a convert's unavailable soil phosphate into available forms. In addition, vermicompost is a high phosphorus content (Table 1). Marinari et al. (2000) found similar increases in phosphates in the soil after the application of organic amendments. The content of available $\mathrm{P}$ was decreased with the application of combined treatments of vermicompost and WTR compared to vermicompost alone. It is worth to mention that similar WTR contained $3315 \mathrm{mg} \mathrm{Al}^{+3}, 406$ $\mathrm{mg} \mathrm{Ca}{ }^{+2}$ and $63.6 \mathrm{mg} \mathrm{Mg}^{+2} \mathrm{~kg}^{-1}$. This indicates the presence of the inorganic components, which may precipitate the $\mathrm{PO}_{4}$ as aluminum phosphate, calcium phosphate and magnesium phosphate, respectively. During the coagulation process, alum is converted to aluminum hydroxides that are similar to aluminum hydroxides which present naturally in soils. These hydroxides can increase the soil's buffering capacity as well as the adsorption and precipitation of specific anions such as orthophosphorus (Basta et al., 2001). Dempsey et al. (1989) reported that alum sludge had a high sportive capacity for $\mathrm{P}$ that reduced plant -available $\mathrm{P}$ and limited plant growth.
The available nitrogen $(\mathrm{N})$ and potassium $(\mathrm{K})$ were increased by the application of vermicompost alone or in combination with WTR which may be attributed to the vermicompost and WTR which have high $\mathrm{N}$ and $\mathrm{K}$ contents (Table 1). The addition of organic matter in the form of mulch, vermicompost and the addition of earthworm casts cause the increase of the biovailability of these elements (Germida and Siciliano, 2000). Soil organic matter and CEC were increased with the addition of vermicompost alone or in combination with WTR to soil. These increases were attributed to high organic matter content of vermicompost and WTR (Table 1).

The increase of soluble calcium and magnesium content with the addition of vermicompost and WTR to soil is caused by high calcium and magnesium content of vermicompost and WTR (Table 1). The improvement of soil physical properties with the addition of organic matter is induced by the reduction in both $\mathrm{Cl}^{-}$and $\mathrm{Na}^{+}$with the leaching water (Levy, 2000).

\section{2. Effect of vermicompost and its mixtures with WTR on grain weight of barley plants}

The application of vermicomposts to soils was associated to an increase in both crop growth and yields (Kale et al., 1992; Arancon et al., 2004). The observed increase in grain weight of barley plants in the soil treated with vermicompost and mixtures of vermicompost and WTR coincided with EC and Na reduction and the increase of both organic matter and available nutrients. The presence of some plant growth influencing substances, such as plant growth hormones and humic acids in vermicomposts, have also been found possible to be a factor that contributes to the increase of plant growth and yields (Arancon et al., $2003 \mathrm{a}, \mathrm{b}$ ). In addition, with the application 
of vermicompost the grain yield was increased. This increase was attributed to the improvement action of compost on the soil physical properties as well as on the nutrients status in the soil which enhances plant growth (El Sanat, 2003).

\section{Conclusions}

The results of this study have confirmed the ability of vermicompost when used alone to improve the salinesodic soils. Moreover, when the soil is treated with mixtures of vermicompost and water treatment residuals (WTR) this gave the highest reduction in salinity, sodicity and soluble $\mathrm{Cl}^{-}$and $\mathrm{Na}^{+}$. Consequently, the grain weight of barley has increased. It was indicated that the application of $10 \mathrm{~g} \mathrm{~kg}^{-1}$ soil at 2:1 (Vermi: WTR) mixed ratio resulted in the best barley growth. The application of WTR with vermicompost to salinesodic agricultural land can be used as an economic and simple alternative for disposal methods of WTR and organic wastes.

\section{References}

Abd El-Hady, B. A., 2007.Effect of zinc application on growth and nutrient uptake ofbarley plant irrigated with saline water. Journal Applied Sciences Research. 3(6), 431-436.

AFNOR, 1991. Matières Fertilisantes et Supports de Culture, Recueil des Normes Françaises. AFNOR, Paris, p. 713.

Arancon, N.Q., Lee,S., Edwards, C.A., Atiyeh, R.M., 2003a. Effects of humic acids and aqueous extracts derived from cattle, food and paper-waste vermicomposts on growth of greenhouse plants. Pedobiologia 47, 741-744.

Arancon, N.Q., Edwards, C.A., Bierman, P., Welch, C., Metzger, J.D., 2003b. Effects of vermicomposts applied to tomatoes and peppers grown in the field, and strawberries grown under high plastic tunnels. Pedobiologia 47, 731-735.

Arancon, N.Q., Edwards, C.A., Bierman, P., Welch, C., Metzger, J.D., 2004. The influence of vermicompost applications to strawberries: Part1. Effects on growth and yield. Bioresource Technology $93,145-153$.

Atiyeh, R.M., Dominguez, J., Subler, S., Edwards, C.A., 2000c. Biochemical changes in cow manure processed by earthworms (Eisenia andrei) and their effects on plant-growth. Pedobiologia 44, 709-724.

Black, C.A., 1982. Methods of Soil Analysis, Part2, 2nd Ed., Ch.8,18. Amer. Soc. Agronomy No.9, Madison, Wisconsin, USA.

Basta, N.T., Zupancic, R.J., Dayton, E., 2001.Evaluating soil tests to predict Bermuda grass growth in drinking water treatment residuals with phosphorus fertilizer. Journal Environmental Quality 29, 2007-2012.

Brady, N.C., 1999. The Nature and Properties of Soils (10Edn.). Macmillan, NewYork, pp: 621.

Bursill, D., 2001. Drinking water treatment e understanding the processes and meeting the challenges. Water Science and Technology: Water Supply 1,177 .

Dempsey, B.A., DeWolfe, J., Hamilton, D., Lee, Y., Liebowitz, R., Elliott, H., 1989. Land application of water plant sludges. pp. 537-543. In Proc. 44th Purdue Industrial Waste Conf., Purdue Univ., West Lafayette. Lewis Publ., Chelsea, MI.

Dominguez, R.,Del Campillo, C., Pena, F., Del gado, A., 2001. Effect of soil properties and reclamation practices on phosphorus dynamics in reclaimed calcareous marsh soils from the guadalquivir valley, spain, Arid land Research Management 15, 203-221.

Edwards, C.A., Dominguez, J., Arancon, N.Q., 2004. The influence of vermicomposts on plant growth 
and pest incidence. In: Mikhail, W.Z.A., Shakir, S.H. (Eds.), Soil Animals and Sustainable Development. pp. 397-420.

El Sanat, G.M., 2003. Effect of amelioration processes on nutrients status in salt affected soils. M. Sc. Thesis, Fac. Agric. Menufiya Univ.

FAO., 1995. Improvement and Production, Drainage and Salinity. An International Source Book. Paris.

Gaffar, M.O., Ibrahim, Y.M., Wahab, D.A., 1992. Effect of farmyard manure and sand on the performance of sorghum and sodicity of soils, Journal India Society Soil Science 40, 540-543.

Germida, J., Siciliano, J., 2000. Microbially Mediated Process. In: Handbook of Soil Science (Sumner, M.E., Ed.), CRC Press, Boca Raton, Florida,pp: C 95-C117.

Grattan, S.R., Oster, J.D., 2003. Use and reuse of saline-sodic water for irrigation of crops. In: Goyal SS, Sharma SK, Rains DW (Eds.), Crop Production in Saline Environments: Global and Integrative Perspectives. Haworth Press, New York, pp. 131-162.

Kale, R.D., Mallesh, B.C., Kubra, B., Bagyaraj, D.J.,1992. Influence of vermicompost application on the available macronutrients and selected microbial populations in a paddy field. Soil Biology and Biochemistry 24, 1317-1320.

Lakhda, A., Scelza, R., Scotti, M. Rao, N., Jedidi, L., Gianfreda C. 2010 The effect of compost and sewage sludge on soil biologic activities in salt affected soil. R.C. Suelo Nutr. Veg. 10 (1) 40 - 47
Levy, G.R., 2000. Sodicity. In: Handbook of Soil Science (Sumner, M.E., Ed.), CRC press, Boca Raton, Florida, pp: 29-63.

Lombi, E., Stevens, D.P., McLaughlin, M.J., 2010. Effect of water treatment residuals on soil phosphorus, copper and aluminium availability and toxicity. Environmental Pollution Pp. 1-7.

Mahmoud, E., Ibrahim, M., Robin, P., Nouraya, A., El-Saka, M., 2009. Rice straw composting and its effect on soil properties. Compost Science \&Utilization 17(3), 146-150.

Mahmoud, E. K. Heavy metal reductions in soils amended with compost and water treatment residuals Compost Science \&Utilization 19 (1), 69-73.

Marinari, S., Masciandaro, G., Ceccanti, B., Grego, S., 2000. Influence of organic and mineral fertilizers on soil biological and physical properties. Bioresource Technology 72, 9-17.

Page, M. A. 1982. Methods of Soil Analysis. Part 2. Academic press, New York.

Qadir, M., Schubert, S., 2002. Degradation process and nutrient constraints in sodic oils. Land degradation \& Development 13.273-294.

SAS. 1996. SAS/Stat User's Guide. Version 6. $4^{\text {th }}$ ed .SAS Institute Inc., Cary. NC.

Stevenson, F.J., 1982. Humus Chemistry: Genesis, Composition, Reactions. John Wiley \& Sons, New York.

Wahdan, A.A., El-Gendi, S.A., Mawgoud, A.S.A., 1999. Amerlioration techniques for sodic soils in Al-Fayoum Oasis. Egypt Journal Soil Science 2, 99-110. 